\title{
Mothers Perception regarding Poisoning among their Preschool Children
}

\author{
Faten Abd El - Samea Mohammed ${ }^{1}$, Doaa Mohamed Sobhy ${ }^{2}$ and Basma Mohamed Abd \\ Elrahman ${ }^{3}$
}

(1) Nursing specialist at Shebin Al Qanater hospital, (2)Assistant Professor of Community Health Nursing, Faculty of Nursing, Benha University, and (3) Lecturer of Community Health Nursing Faculty of Nursing -Benha University

\begin{abstract}
Background: Poisoning is a term used to describe an event where the poisonous substances have entered the body through breathing, mouth, blood vessels, eating, injections and leads to the destruction and death of the body's cells. The aim of this study was to assess Mothers perception regarding poisoning among their preschool children. Research design: A descriptive study design was utilized to conduct this study. Setting: This study was conducted at Toxicology Unit at Benha University Hospital in Benha City, Egypt. The sample: Purposive sample of $25 \%$ of all poisoned children attended the previously mentioned setting with their mothers (130 mothers). Tools of data collection: Two tools were used, I. An interviewing questionnaire was used, It consisted of four parts: First part: Socio demographic characteristics of the mothers. This part included two items. A) Mother's demographic characteristics B) Child's characteristic. Second part: Was concerned with the child health status. Third part: Was concerned with knowledge of mothers regarding to poisoning among their preschool age children. Forth part: An observational checklist was used to observe mothers'preventive practices. II. Scale to measure the attitude of mothers. Results: $60.7 \%$ of mothers had poor total knowledge regarding poisoning among preschool age children, $67.7 \%$ of mothers had unsatisfactory total of reported practices about poisoning, $62.3 \%$ of mothers had total negative attitude about poisoning of preschool children. Conclusion: There were a positive statistically significant correlation between total knowledge and attitude scores, between total knowledge and total reported practices scores and between attitude scores and total reported practices regarding poisoning among their preschool age children. Recommendations: All possible forms of mass media should be utilized to help in disseminating information about poisoning in children.
\end{abstract}

\section{Key words: Mothers Perception, Poisoning, Preschool Children}

\section{Introduction}

Preschool age years are the period from birth to less than six years old and are not in full-time education. Children under six years are the future of any country and precious resources of sustainable development of the human society. Improving nutrition and health status of children is the basic for realization of the comprehensive development and the transformation of any country (Centers for Disease Control and Prevention, 2019).

Poisoning is one of the major public health problems and is one of the most common causes for referring to emergency departments. 


\section{Mothers Perception regarding Poisoning among their Preschool Children}

According to World Health Organization (WHO), it is estimated that 193,460 people died worldwide from unintentional poisoning in 2012. Of these deaths, $84 \%$ occurred in low and middle-income countries. Most children under 5 years die from unintentional injuries that are attributable to the environment, as poisoning, falls, and drowning. Among various external reasons for death in children at the age range from 1 to 14 years, poisoning has been located in fourth-place after road injuries, fires and drowning. Children are also exposed to harmful chemicals through food, water, air and products around them (Shahkolai et al., 2019).

Poisoning can occur in any individual, irrespective of age. Other considerations related to poisoning are as follows; around $70 \%$ of poisoning cases occur in children and over $90 \%$ of these are accidental: acute poisoning of children is one of the most common types of emergency and a cause of child mortality particularly in developing countries (Shirdelpour et al., 2017). Safe storage, community education, and enhanced parental supervision are important interventions for prevention of accidental poisonings (Matalova et al., 2019).

The most significant types of poisoning agents are common pharmaceuticals (drug over dose), household products such as cleaning agents, pesticides, poisonous plants and bits from insects. Kerosene, gases, organophosphates, aluminum phosphide, carbon monoxide and food poisoning are the primary cause of unintentional poisoning in children younger than five years (Bandyopadhyay et al., 2020).

The best way to prevent poisoning is to avoid contact with harmful substances. Keep all household substances out of the reach of children, should put them in high or locked cabinets. This includes medicine, cleaning products, and other harmful chemicals. Also can child proof the house with safety locks and guards. Wear protective clothing, like gloves, when they use cleaners and chemicals. Avoid using pesticides and similar chemicals inside the house. Try to find non-chemical solutions. If these chemicals are to be used inside, keep the area well aired. Don't mix chemicals. They may become poisonous when mixed. Keep medicines and chemicals in their original containers (Mintegi et al., 2015). Label everything inside the medicine cabinet. Get rid of old or expired medicines and household products. Dispose of them safely, per FDA and hazardous waste guidelines. Call poison control for more information. Follow all product label directions. Have all gas-, oil-, and wood-fueled appliances serviced regularly. Be sure they are well vented. Install a carbon monoxide detector in the home. Regularly test and replace the batteries (American Academy of Pediatrics, 2019).

Community health nurse has an important role in prevention of poisoning according to three levels of prevention. Primary prevention is efforts to reduce the incidence of poisoning through health promotion and education. Secondary prevention is the early detection and control of poisoning. Tertiary prevention involves reducing of complications and disabilities resulting from poisoning (AbdelMordy, 2016).

\section{Significance of the study}

In 2015, the American Association of Poison Control Center (AAPCC) reported that more than 1.3 million children were exposed to 
poisoning substances, $40 \%$ of whom were children less than 3 years old (Tobaiqy et al., 2020). Acute poisoning among children is a growing concern among health professionals caring for children. The patterns of poisoning are variable based on sociocultural factors (Dayamanne et al., 2020).

\section{Aim of the study}

The aim of this study was to assess mothers perception regarding poisoning among their preschool children.

\section{Research questions}

- What is the mothers' knowledge regarding poisoning of their preschool children?

-What is the mothers` attitude regarding poisoning of their preschool children?

-What is the mothers' reported practice regarding poisoning of their preschool children?

-What is the relation between mother's knowledge, and their reported practices regarding poisoning of their preschool children?

- What are the most common types of poisoning among preschool children?

\section{Subjects and Method}

\section{Research design:}

A descriptive research design was utilized to conduct this study. This methodology focuses more on the "what" of the research subject rather than the "why" of the research subject).

\section{Setting:}

This study was conducted at Toxicology Unit at Benha University Hospital in Benha City, Egypt. It was characterized by high attendance rate of mothers of children with poisoning.

\section{Sampling:}

Purposive sample of $25 \%$ of all poisoned children attended the previously mentioned setting with their mothers (130 mothers).

Tools of data collection: Two tools were used to collect the data:

Tool (I): A structured interviewing questionnaire: It was developed by the investigator based on reviewing related literatures. It was written in simple clear Arabic language. It was comprised of four parts:

First part: Was concerned with demographic characteristics of the mothers. This part included two subparts. A) - Mother's demographic characteristics. It consists of six closed ended questions (multiple choice types) covering areas such as age, marital status, residence, level of educational, occupation and income.

B) - Child's characteristic which consisted of eight closed ended questions (multiple choice type) covering areas such as gender, age, number of children in the family, child's ranking order among siblings, the person caring for the child, the current type of poisoning, the child previously poisoned experience and type of poisoning .

Second part: Was concerned with the child's health status which consisted of eight closed ended questions (multiple choice type) covering areas such as suffering from any 


\section{Mothers Perception regarding Poisoning among their Preschool Children}

health problems, type of health problems, medications taken regularly, admission to hospitals before, psychological problems and type of psychological problems.

Third part: Was concerned with knowledge of mothers regarding poisoning among their preschool age children which consisted of ten closed ended questions (multiple choice type) covering areas such as meaning of poisoning, types of toxic substances, method of exposure to poisoning, signs and symptoms of poisoning, common toxic substances from household products, the most common medicines leading to poisoning, factors leading to increased severity of child poisoning, evidence of poisoning, factors leading to identification of substance toxicity and source of information about poisoning.

\section{Scoring system:}

Knowledge score for each answer was given as follows:

$$
\begin{aligned}
& 2=\text { complete and correct knowledge. } \\
& 1=\text { incomplete and correct knowledge. } \\
& 0=\text { don't know. }
\end{aligned}
$$

The total score of knowledge $=18$.

The total knowledge score was considered good if the score of the knowledge $\geq 75 \%$ ( $>13$ points), while considered average if it equals $50<75 \%$ (13-9 points), and considered poor if it is $<50 \%$ ( $<9$ points).

Forth part: A checklist to assess mothers' reported practices regarding A-Preventive practices for poisoning. B- First aid for poisoning

A- Mothers' reported practices regarding preventive practices for poisoning included 4 items; making home safe (9 items), preventive practices for medication risks (4 items), preventive practices for poisoning from cleaning supplies and chemicals (9 items).

B- First aid for poisoning included 4 items; first aid for poisoning by swallowing (6 items), poisoning through skin (4 items), poisoning through the eyes (5 items), and poisoning by inhalation ( 5 items).

\section{Scoring system:}

The scoring system for mothers' reported practices was scored as:

$$
1 \text { = Done. }
$$

$0=$ Not done.

The total practices score $=42$ score .

The total practices score was considered satisfactory if the score $\geq 60 \% \quad(\geq 25$ points), and considered unsatisfactory if it< $60 \%$ ( $<25$ points).

Tool (II): Scale to measure the attitude of mothers adopted from Abd- El wahab, (2019) and modified by the researcher. It was translated into Arabic by the researcher which consist of thirteen items as follows: Thinking that poisoning is dangerous and worrying, thinking the poisoning is affecting the child's vision, thinking that the poisoning will affect the child's performance later in school, believing that most cases of poisoning in children occur at home, thinking that poisoning is caused by drugs, thinking that fatal poisoning is higher among preschoolers, thinking that children who have been poisoned are less likely to have it again, believing that substances toxicity is determined by the dose per kilogram of body weight, thinking that animal bites or insect bites are among the causes of poisoning, thinking that any substance can be toxic when 
ingested in large enough quantities, thinking that child's home environment can increase the risk of poisoning, thinking that charcoal tablets stop the toxin from being absorbed and believing that if a battery is swallowed, medical help is seek immediately at emergency department.

\section{Scoring system:}

Each response has three levels of answers: "Agree", "uncertain" and "disagree". These were respectively scored 2, 1 and 0 for positive items, and reversed for negative items.

The total score of attitude score $=26$ points. The total attitude score was considered positive if the score is $\geq 75 \% \quad(\geq 19$ points), and considered negative if it equal $<75 \%(<19$ points).

\section{Content validity and reliability:}

Tools of the study were given to a group of 5 experts in the field of Community Health Nursing who reviewed the tools for clarity, relevance, comprehensiveness and applicability. The panel ascertained the face and content validity of the tools. Reliability for knowledge = 0.85 , practice $=0.82$ and attitude $=0.68$.

\section{Ethical considerations:}

All ethical issues were assured; oral consent has been obtained from each mother before conducting the interview and given them a brief orientation to the purpose of the study. They were also reassured that all information gathered would be kept confidentially and used only for the purpose of the study. Mothers had the right to withdraw from the study at any time without giving any reasons.

\section{Pilot study:}

The pilot study was carried out on $10 \%$ of mothers included in the sample size. The pilot study aimed to assess the tool applicability, clarity and objectivity. As well as to estimate the time needed for data collection. According to the results obtained from data analysis: items correction, modification, omission and addition were done as needed.

\section{Field work:}

The data was collected from mothers who attended in the previously selected hospital through interview. The study was conducted at a period of six months which started from the beginning of July 2020 to the end of December 2020. The investigator attended two days/week from 9.00 am to 12 mid-day. The average number of interviewed mothers was between 1-3 mothers/day. Each interviewed mother took about 30 to 45 minutes to fill the sheet.

\section{Statistical analysis:}

Data were analyzed using the statistical software package for social science (SPSS) version 26. Qualitative data were expressed as numbers and percentages. Chi-square test $\left(\mathrm{X}^{2}\right)$ was used to examine the relation between qualitative variables. Pearson correlation (r) was used to detect associations between quantitative variables. 


\section{Mothers Perception regarding Poisoning among their Preschool Children}

\section{Results:}

Table (1): Shows that, $40.8 \%$ of mothers aged 25 to less than 30 years or more with mean age was $28.34 \pm 6.01$, while $94.6 \%$ were married, $64.6 \%$ of them living in rural area and $57.6 \%$ had secondary education. Regarding occupation of mothers $73.8 \%$ were housewives and $60 \%$ of them had adequate income per month

Table (2): Shows that, $56.9 \%$ of children were males and $53.1 \%$ of them aged 4 years with mean age were $4.06 \pm 0.86$. Regarding to the child ranking, $43.9 \%$ of families had three children or more and $40 \%$ of children were middle in ranking among siblings. $80.0 \%$ of preschool children were cared for by mothers and $6.2 \%$ of the children were previously poisoned.

Figure (1): Illustrates that, $42.3 \%$ of preschool age children were poisoned from corrosive agents, $23.8 \%$ from insecticide while $11.5 \%$ of the studied preschool age children were poisoning from medication poisoning, $7.7 \%$ of them from kerosene poisoning, $7.7 \%$ of them from toxic gases and $6.9 \%$ of them from food poisoning

Figure (2): Illustrates that, $67.7 \%$ of mothers had unsatisfactory total practices level about poisoning and $32.3 \%$ of them had satisfactory total level of practices about poisoning.

Figure (3): Illustrates that, $62.3 \%$ of mothers had total negative attitude about poisoning of preschool children while $37.7 .3 \%$ of them had total positive attitude.

Table (3): There were positive statistically significant correlations between total attitude, total knowledge and total reported practices regarding to poisoning among their preschool age children. 
Table (1): Distribution of mothers of preschool age children regarding to their socio demographic characteristics $(n=130)$.

\begin{tabular}{|c|c|c|}
\hline Demographic characteristics & No & $\%$ \\
\hline \multicolumn{3}{|l|}{ Age in (years) } \\
\hline $20-$ & 29 & 22.3 \\
\hline $25-$ & 53 & 40.8 \\
\hline $30-$ & 24 & 18.5 \\
\hline $35-$ & 16 & 12.3 \\
\hline$\geq 40$ & 8 & 6.1 \\
\hline \multicolumn{3}{|c|}{ Mean \pm SD $=28.34 \pm 6.01$} \\
\hline \multicolumn{3}{|l|}{ Marital Status } \\
\hline Married & 123 & 94.6 \\
\hline Divorced & 5 & 3.8 \\
\hline Widowed & 2 & 1.5 \\
\hline \multicolumn{3}{|l|}{ Residence: } \\
\hline Rural & 84 & 64.6 \\
\hline Urban & 46 & 35.4 \\
\hline \multicolumn{3}{|l|}{ Level of Education } \\
\hline Illiterate & 4 & 3.1 \\
\hline Basic education & 21 & 16.2 \\
\hline Secondary education & 75 & 57.6 \\
\hline University education & 30 & 23.1 \\
\hline \multicolumn{3}{|l|}{ Occupation } \\
\hline Employee & 23 & 17.7 \\
\hline Free work & 11 & 8.5 \\
\hline Housewife & 96 & 73.8 \\
\hline \multicolumn{3}{|l|}{ Income } \\
\hline Adequate and save & 20 & 15.4 \\
\hline Adequate & 78 & 60.0 \\
\hline Inadequate & 32 & 24.6 \\
\hline
\end{tabular}


Table (2): Distribution of preschool age children regarding to their demographic characteristics $(\mathbf{n}=130)$.

\begin{tabular}{|c|c|c|}
\hline Children demographic characteristics & No & $\%$ \\
\hline \multicolumn{3}{|l|}{ Gender } \\
\hline Male & 74 & 56.9 \\
\hline Female & 56 & 43.1 \\
\hline \multicolumn{3}{|l|}{ Age in (years) } \\
\hline 3yrs & 33 & 25.4 \\
\hline $4 y r s$ & 69 & 53.1 \\
\hline $5-6 y r s$ & 28 & 21.5 \\
\hline \multicolumn{3}{|c|}{ Mean $\pm \mathbf{S D}=4.06 \pm .86$} \\
\hline \multicolumn{3}{|l|}{ Number of children in the family: } \\
\hline One child & 28 & 21.5 \\
\hline Two children & 45 & 34.6 \\
\hline Three or more children & 57 & 43.9 \\
\hline \multicolumn{3}{|l|}{ Child's ranking among siblings: } \\
\hline The first & 30 & 23.1 \\
\hline Middle & 52 & 40.0 \\
\hline The last & 48 & 36.9 \\
\hline \multicolumn{3}{|l|}{ The person caring for the child: } \\
\hline The mother & 104 & 80.0 \\
\hline The father & 3 & 2.3 \\
\hline One of the brothers & 8 & 6.2 \\
\hline Grandpa / Grandma & 15 & 11.5 \\
\hline \multicolumn{3}{|l|}{ The child previously poisoned: } \\
\hline Yes & 8 & 6.2 \\
\hline No & 122 & 93.8 \\
\hline \multicolumn{3}{|l|}{ Type of poisoning $(n=8):$} \\
\hline Medical poisoning & 2 & 25.0 \\
\hline Chemical poisoning & 5 & 62.5 \\
\hline Food poisoning & 1 & 12.5 \\
\hline
\end{tabular}




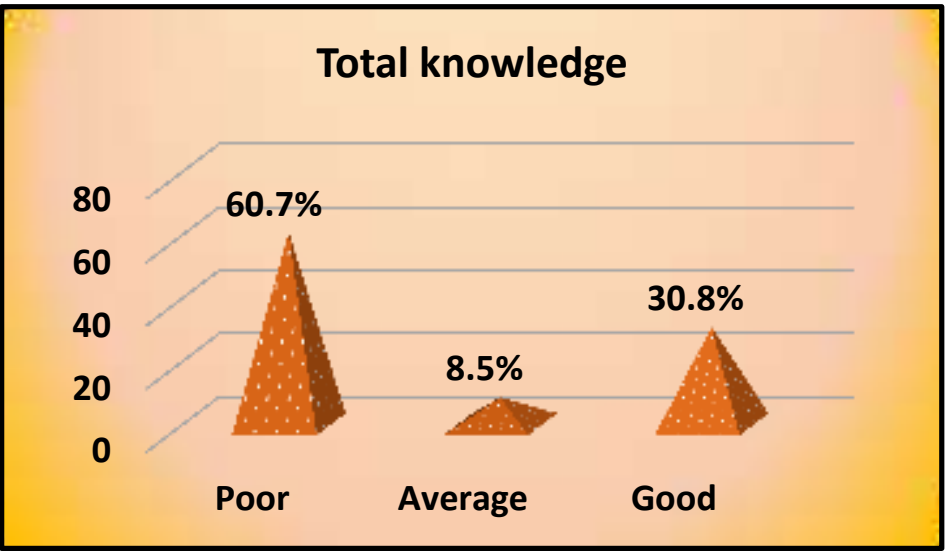

Figure (1): Percentage distribution of mothers regarding to total knowledge about poisoning among their preschool age children $(n=130)$.

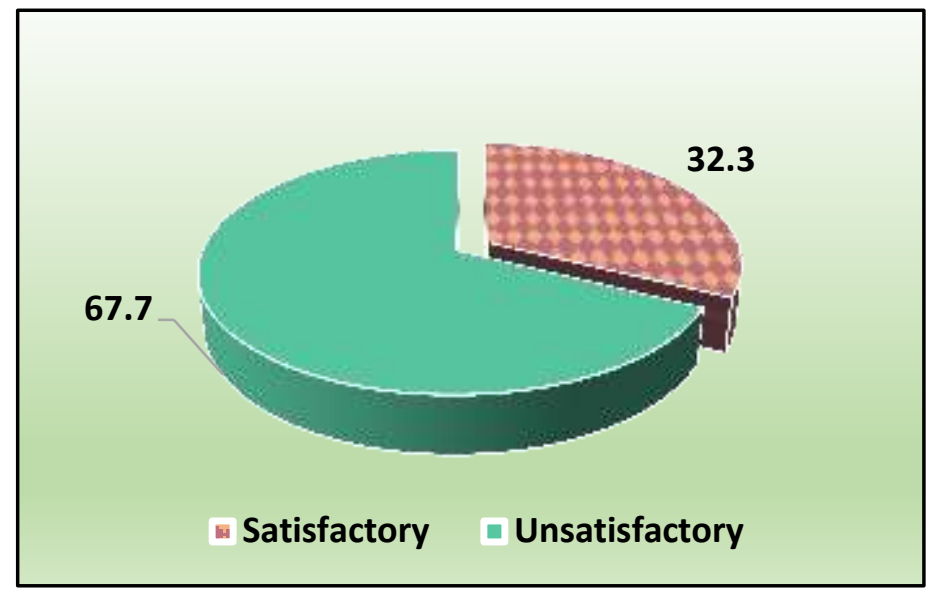

Figure (2): Percentage distribution of the studied mothers regarding to their total reported practices score about poisoning among their preschool age children $(n=130)$.

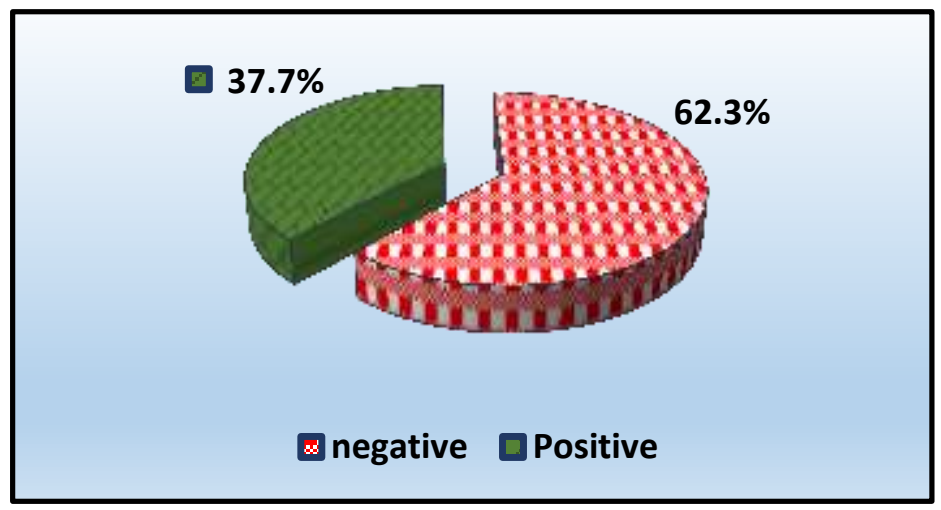

Figure (3): Percentage distribution of mothers regarding to their total attitude about poisoning among their preschool age children $(n=130)$. 
Table (3): Correlation coefficient between mothers' total knowledge, attitude and reported practices regarding to poisoning among their preschool age children $(n=130)$.

\begin{tabular}{|c|c|c|c|c|c|c|}
\hline \multirow{2}{*}{ Variables } & \multicolumn{2}{|c|}{ Total attitude } & \multicolumn{2}{c|}{ Total knowledge } & \multicolumn{2}{c|}{$\begin{array}{c}\text { Total reported } \\
\text { practices }\end{array}$} \\
\cline { 2 - 7 } & $\mathbf{R}$ & $\mathbf{p}$ value & $\mathbf{r}$ & $\mathbf{p}$ value & & p value \\
\hline Total attitude & - & - & .781 & $0.05 *$ & - & - \\
\hline Total knowledge & - & - & - & - & .862 & $0.05 *$ \\
\hline Total reported practices & .786 & $0.05 *$ & - & - & & \\
\hline
\end{tabular}

*statistically significant at $\mathbf{p} \geq 0.5$

\section{Discussion}

Accidental poisoning is a serious international problem. It is likely to remain one of the most common medical emergencies that confront physicians and casually medical offices at any time $90 \%$ of accidental poisoning involved children under the age of five years. Poisoning in children is always an accident due to lack of supervision of the child or to carelessness in leaving poisonous substances within the child's reach (El Guindi., et al 2020). Ninety percent of poisoning in children admitted occur among children below 5 years of age with the peak at 2 years of age and is seen more frequently among low socioeconomic. This can be attributed to lack of parents`knowledge about toxic substances. Poisoning usually from toxic substances kept in the home is one of the most serious causes of illness and death in childhood. Poisoning is the result of the interaction of the agent, the child and family environment (El-Emary., et al 2019).

According to socio demographic characteristics of mothers, this study revealed that two fifths of mothers aged from 25 to 30 years with mean age \pm SD 28.34 \pm 6.1 .This finding agreed with Moshtohory et al. (2018), who conducted a study on the "Effect of guiding program on mothers' health awareness regarding household poisoning of their children less than six years old in rural areas, Egypt ", $(\mathrm{N}=50)$, and found that $34 \%$ of mothers aged 25 to 30 years with mean age of \pm SD $33.5 \pm 2.9$ years.

Concerning to marital status of mothers, the current study revealed that most of studied mothers were married. This finding agreed with Akturk \& Erc. (2016), who conducted a study on "Determination of knowledge, attitudes and behaviors regarding factors causing home accidents and prevention in mothers with a child aged 0-5 years, Malatya, Turkey" ( $\mathrm{N}=340$ ), and found that most of the studied sample were married.

Regarding residence, more than three fifths of mothers in the current study lived in rural areas. This finding agreed with Anwar et al. (2014), who conducted a study on "Clinical profile of kerosene poisoning in a tertiary level hospital in Bangladesh" ( $\mathrm{N}=56)$, and found that more than three fifths of mothers lived in rural areas.

As regards educational level, more than half of mothers in the study sample had secondary education. This finding agreed with Megahed et al. (2016), who conducted a study on "Knowledge, attitude and practice of rural mothers towards home injuries among children 
under 5 years of age in Menouf DistrictMenoufia Governorate, Egypt," ( $\mathrm{N}=270)$, and found that two fifths of mothers had secondary education.

Also, regarding to occupation of mothers, this study showed that more than two thirds of mothers are housewife, this finding agree with Sivri \& Ozpulat. (2016), who conducted a study on "Mothers' knowledge levels related to poisoning, Turkey", $(\mathrm{N}=289)$, and found that more than two thirds of mothers are housewife

Concerning income, three fifths of mothers in the current study had adequate income. This finding was consistent with Zyoud et al. (2019), who conducted a study on "Knowledge, attitude and practices among parents regarding food poisoning acrosssectional study from Palestine", $(\mathrm{N}=412)$, and found that slightly less than three fifths of the studied sample had average income.

According to child's characteristics, this study showed that more than half of children were male. This finding was in the same line with the study done by Basu. (2016), who conducted a study on "Socio-demographic factors, symptoms, complications and treatment of kerosene oil poisoning in children, Kalyani, India", $(\mathrm{N}=412)$, and reported that more than two thirds of children were male. This finding also was agree with the study done by El Seifi et al. (2018), who conducted a study on the "Effect of community-based intervention on knowledge, attitude, and self-efficacy toward home injuries among Egyptian rural mothers having preschool children", $(\mathrm{N}=244), \quad$ and reported that three fifths of children were male.
Regarding the age of children, the present study finding showed that more than half of children aged five years. This might be due to criteria of selection of sample and poisoning is common in preschool children. However this finding disagreed with Singh \& Gurung. (2018), who performed a study" Factors contributing to kerosene oil poisoning in children, Lahore, Pakistan", $(\mathrm{N}=100)$, and reported that approximately two fifths of children aged three years old.

Also number of children in the family, the present study finding showed that approximately two fifths of the families had three or more children. This finding agree with Abel Galil et al. (2018), who conducted a study on "Mother's Knowledge and Practices Regarding care of the Children with Accidental Poisoning at Zagazig University", $(\mathrm{N}=251)$, and reported that approximately two fifths of families had 2-6 children.

Regarding to the person caring for the child, the present study finding showed that majority of mothers are the ones caring for their child. This finding was agree with Assar et al. (2019), who conducted a study on "Acute poisoning in children, Pakistan" $(\mathrm{N}=70)$, and reported that more than three fifths of mothers is caring for their child.

Regarding to the history of previous poisoning, the present study finding showed that most of children had no history of previous poisoning. This finding agreed with Moshtohry et al. (2018), who conducted a study on the "Effect of guiding program on mothers' health awareness regarding household poisoning of their children less than six years 


\section{Mothers Perception regarding Poisoning among their Preschool Children}

old in rural areas, Egypt ", $(\mathrm{N}=50)$, and reported that three quarter of children had no history of previous poisoning.

According to total knowledge score of the mothers regarding poisoning, the present study revealed that three fifths of mothers had poor knowledge about poisoning. This was consistent with Abel Galil et al. (2018), who conducted a study on "Mother's Knowledge and Practices Regarding Care Of the Children with Accidental Poisoning at Zagazig University", $(\mathrm{N}=251)$, and reported that three fifths of mothers of children with poisoning had poor knowledge. This might be due to low educational level of the mothers.

According to reported practices score of studied mothers regarding poisoning, the present study revealed that two thirds of mothers had unsatisfactory total reported practices level about poisoning. This finding was consistent with Zyoud et al. (2019), who conducted a study on "Knowledge, attitude and practices among parents regarding food poisoning across- sectional study from Palestine", $(\mathrm{N}=412)$, more than two thirds of mothers had unsatisfactory total reported practices level about poisoning. This was consistent with Abel Galil et al. (2018), who conducted a study on "Mother's Knowledge and Practices Regarding Care Of the Children with Accidental Poisoning at Zagazig University", $(\mathrm{N}=251)$, and reported that more than three fifths of mothers had unsatisfactory total reported practices level about poisoning.

According to total attitude score of studied mothers regarding poisoning, the present study revealed that more than three fifths of mothers had total negative attitude about poisoning of preschool children. This finding was consistent with Barghash et al (2015), who conducted a study on "Knowledge, Attitude and Practice about Household Poisoning in Saudi Arabia"(N=102), and found that more than two thirds of mothers had total negative attitude about poisoning of preschool children. This might be due to most of the studied sample are from rural area and they have poor knowledge.

In the present study results showed that there was a positive statistically significant correlation between total knowledge and attitude scores, between total knowledge and total reported practices scores and between attitude scores and total reported practices regarding to poisoning among their preschool age children. This finding agreed with Abel Galil et al. (2018), who conducted a study on "Mother's Knowledge and Practices Regarding Care Of the Children with Accidental Poisoning at Zagazig University" showed that there was a positive statistically significant correlation between total knowledge and total reported practices scores. This might be due to knowledge play an important role in changing behavior leading to change of practices.

\section{Conclusion:}

Approximately three fifths of mothers had poor knowledge and minority of them had average total knowledge, while less than third of them had good total knowledge about poisoning among preschool age children. More than three fifths of mothers had total negative attitude about poisoning of preschool children. More than two thirds of mothers had unsatisfactory total practices level about 
poisoning. There were a positive statistically significant correlation between total knowledge and attitude scores, between total knowledge and total reported practices scores and between attitude scores and total reported practices regarding poisoning among their preschool age children.

\section{Recommendations:}

1- Health education program should be developed for mothers had children to educate them with the most current information and practices regarding poisoning among preschool children.

2- Booklets should be available and distributed to all mothers about the poisoning and health-related practices.

3- $\quad$ A special place should be prepared at all government centers for providing health education regarding poisoning.

4- $\quad$ Further studies about corrosive agents poisoning, prevention and first aid among mothers of preschool children.

\section{References}

Akhtar, S., Rehman, A., Bano, S., and Haque, A. (2015): Accidental Phosphine Gas Poisoning with Fatal Myocardial Dysfunction in Two Families, Journal of the College of Physicians and Surgeons Pakistan; 25 (5):Pp. 378-379.

Anwar, S., Rahman, A., and Houqe, A. (2014): Clinical Profile of Kerosene Poisoning in a Tertiary Level Hospital in Bangladesh, Bangladesh Journal of Child Health; 38(1): Pp 11-4.

Assar, S., Hatami, S., Lak, E., and Pipelzadeh, M. (2019): Acute poisoning in children, Pakistan, Journal of medical sciences; 25(1):51-54.
Barghash, S., El-Tit, A., and Al-jemily, H. (2016): Knowledge, Attitude and Practice about Household Poisoning in Saudi Arabia, Advances in medical and Pharmaceutical Sciences Journal; 6(2): Pp 1-12.

El Guindi,.K. (2016): Common poisoning in infancy and childhood, published thesis for master degree. Ain Shams University, pp 5758.

El-Emary, M., Heshmat, S., Mesriga and El Mehi(2019):: A dtisy of patient with acute poisoning admitted to the Major Tanta Hospital, Forensic Medicine and Toxicology Department, pp.600-620.

Tobaiqy, M., Asiri, B., Sholan, A., Alzahrani, Y., and Al-kathwwri, A. (2020): Frequency and Management of Acute Poisoning Among Children Attending an Emergency Department in Saudi Arabia, Journal pharmacy; 8(4) :189.

-Mohamed, S., Shokry, E., and Abdou, S. (2018): Mother ' Knowledge and practices regarding care of the children with accidental poisoning; 2(14):34-47.

- Moshtohory, M., Mohamed, A., and Kunswa, M. (2018):Guiding program on mothers health awareness regarding household poisoning of their children less than six year old,IOSR Journal of nursing and health science; 4(7): 75-88.

-Megahed, M., Kalil, N., Ibrahim, R., and Eldisoki, R. (2016): Knowledge, attitude and practice of rural mothers towards home injuries among children under 5 years of age in menouf district - menoufia governorate, Egypt; 4(29):1033-1039.

-Shirdelpour, K., Zahra, S., Mirzaei, M., and Kazem, E. (2017):poisoning and its related factors in children under 6 years old in rasht, 
Holistic Nursing and Midwifery Journal; 2(27):85:92.

Abdel-Mordy, M. (2016): Evaluation of Home Health Care Intervention for Cerebral Stroke Patients and Their Caregivers in Benha City, Doctorate Thesis, Benha University, Faculty of Nursing, Pp.22,29.

American Academy of Pediatric (2019): Poisoning Prevention and Treatment Tips, Available at https://www. healthy children. Org. accessed on 10of December 2020.

Bandyopadhyay, A., and Mandal. (2017): Clinical profile and outcome of Acute Poisoning in Children and Adolescent in A Tertiary Care Center, Asian Journal of Medical Sciences; 8 (1):Pp 75-77.

Centers for Disease Control and Prevention (2019): Treatment for Poisoning in Children, Available at https://nyulangone.org/conditions/ poisoning-in-children/treatments/treatment-forpoisoning-in-children. Accessed on 6 of December 2020.

Matalova, P., Poruba, M., Wawruch, M., Ondra, P., and Urbánek, K. (2019): Acute medication poisoning causing hospital admissions in childhood: a 3-year prospective observational single-center study," Physiological Research; 68(1) : Pp31-38.

Mintegi, S., Esparza, M., Gonzálezc, J., Rubio, B., and Sánchez, F. (2015): Recommendations for the Prevention of Poisoning, Anales de Pediatría; 83(6): 1-440.

Shahkolai, F., Bandehelahi, K., Shahanjarini, A., and Fahadian, M. (2019): The factors related to mother's beliefs and behaviors concerning the prevention of poisoning among children under the age of five, using the Health Belief Model, The Turkish Journal of Pediatric; 61: Pp:749-756. 


\section{إدراك الأمهات تجاه التسمم بين أطفالهن في سن ما قبل المدرسة فاتن عبالسميع محم - دعاء محم صبحى- بسمة محم عبدالرحمن}

تختلف أنماط التسمم بناء على العوامل الإجتماعية والثقافية ويعد التسمح مشكلة صحية ذات اهمية في

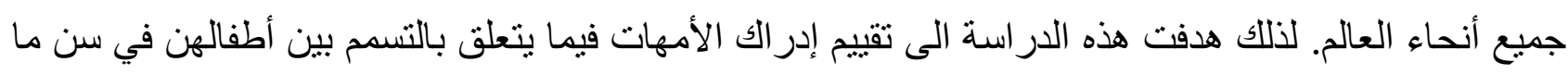
قبل المدرسة وقد اجريت هذه الدر اسة فى وحدة السموم بمستشفى بنها الجامعى بمدينة بنها. و أسفرت النتائج علي

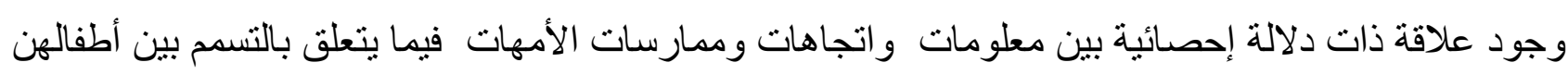

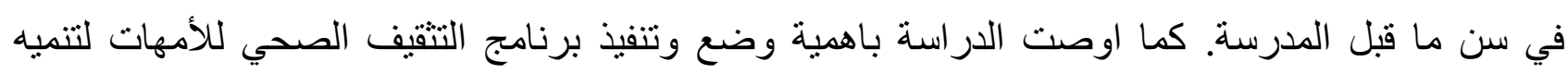
المعلومات و الممارسات المتعلقة بالتسمم بين أطفال ما قبل المدرسة. 